\title{
Feeding behavior and sensorimotor functioning in rats with unilateral medial forebrain bundle damage
}

\author{
D. C. UGURU-OKORIE \\ University of Ibadan, Ibadan, Nigeria
}

\begin{abstract}
Seven male Wistar albino rats that had sustained an extensive 6-hydroxydopamine-induced unilateral MFB lesion suffered long-lasting reductions in body weight and food intake and an enhancement of food spillage relative to vehicle-microinjected controls. The lesioned subjects also exhibited persistent circling in the direction of the lesioned hemisphere and used virtually only the ipsilateral forepaw to operate a lever to obtain food in an operant chamber. There was, however, no significant correlation between food intake or spillage, on the one hand, and leverpresses or rotations, on the other. It is suggested that the observed changes in feeding and forepaw use may be distinct and independent effects of MFB damage.
\end{abstract}

In experimental animals, bilateral nigrostriatal damage causes aphagia and adipsia (Ungerstedt, 1971; Zigmond \& Stricker, 1972) and leads to marked weight loss (Boyle \& Keesey, 1975; Powley \& Keesey, 1970). Unilateral lesions interrupting the nigrostriatal pathway also produce severe weight loss (Baez, Ahlskog, \& Randall, 1977; Uguru-Okorie, 1981) coupled with reduced food intake and enhanced food spillage (Uguru-Okorie, 1981).

The impairment of food intake by nigrostriatal damage does not appear to be associated with a disruption of gustatory mechanisms (Marshall, Richardson, \& Teitelbaum, 1974). On the other hand, an impressive body of empirical evidence suggests that at least part of the impairment of feeding and drinking in animals with nigrostriatal damage may be due to lesion-induced sensorimotor dysfunction. Thus, for example, bilateral nigrostriatal lesions cause akinesia (Fibiger, Zis, \& McGeer, 1973a, 1973b; Oltmans \& Harvey, 1972), and unilateral damage impairs the ability of an animal to orient to stimuli applied to the side opposite to the lesion side (Marshall et al., 1974) as well as its ability to use its contralateral paw to resist gravitational pull (Marshall et al., 1974). In a recent study (Uguru-Okorie, 1982), a unilateral medial forebrain bundle lesion, which severely depleted forebrain dopamine, produced a reversal of forepaw preferences in rats with a preoperative preference for the paw contralateral to the lesioned hemisphere.

This study was carried out in the laboratories of the M.R.C. Brain Metabolism Unit, Edinburgh. The author wishes to acknowledge with deep gratitude the immense help received during the study from David M. Vowles, Head of the Department of Psychology, University of Edinburgh, from Gordon W. Arbuthnott, of the M.R.C. Brain Metabolism Unit, Edinburgh, and from their two departments. Professor Vowles's constant encouragement throughout the study is especially appreciated. Many thanks are also due Mrs. Anne Aderogba of the Department of Geography, University of Ibadan, for kindly preparing the figure. The author's mailing address is: Department of Psychology, University of Ibadan, Ibadan, Nigeria.
The present study was designed to examine the relatedness or nonrelatedness of the effects of MFB damage on feeding and operant chamber behavior. The goal of the study was to gain some insight into the question of possible sensorimotor involvement in the feeding deficits observed in animals with an extensive lesion of the MFB.

\section{MATERIALS AND METHODS}

\section{Subjects}

The subjects were 13 male Wistar albino rats weighing between 180 and $200 \mathrm{~g}$ at the time of surgery. For the portion of the experiment concerned with feeding behavior, the animals were housed singly in individual plastic cages measuring $38 \times 25 \times 18 \mathrm{~cm}$. For the operant behavior phase, they were housed in twos in standard breeding cages measuring $56 \times 38 \times 18 \mathrm{~cm}$. Throughout the investigation the subjects were placed on a 12 -h reverse daylight schedule, and had food and water ad lib, except that they were deprived of food for predetermined periods of time when their reactions and responses to food deprivation were to be observed or when they were to be run in a food-rewarded operant behavior situation.

\section{Procedure}

Following a 7-day acclimatization period in the laboratory conditions, during which the rats were housed individually, each rat was provided with water and a known amount of food and its body weight was measured. Next day, data were collected as follows: amount of food missing from the food-hopper, amount of food spilled, and body weight. Each day after the record-taking session, the rats were returned to clean cages that had fresh supplies of water and food. Seven such daily sessions were carried out on successive days, and then the subjects underwent surgery.

Surgery was completed for all subjects within $4 \mathrm{~h}$ after data were taken for the 7 th day. Food and water were restored at the end of surgery, and the rats were left for $16-20 \mathrm{~h}$ to recover from the trauma of surgery. Then the rats were placed in clean cages with fresh supplies of food and water in exactly the same manner as prior to surgery. The first postoperative records were taken $44 \mathrm{~h}$ after the completion of surgery. Data were collected for 14 successive days, and then the rats were deprived of food for $24 \mathrm{~h}$ and weight loss was determined. Food was then restored, and $24 \mathrm{~h}$ later measurements were taken of food intake and food spillage as well as body weight. The subjects were transferred to larger cages, measuring $56 \times 38 \times 18 \mathrm{~cm}$, where they were housed in twos for 10 weeks. At the end of this period, the rats were deprived 
of food for $24 \mathrm{~h}$ and introduced into an operant chamber (Campden Instruments). The chamber had two identical levers and a food dispenser between them.

The animal's behavior was shaped by the placement of food (45-mg pellets, Campden Instruments) on the two levers and in the food hopper; each push that depressed either lever was rewarded with a single food pellet. Each subject was given an initial training session of $1 \mathrm{~h}$ and, unless the learning criterion of 20 leverpresses followed immediately by food collection and consumption was reached, a further .5-h session was given $2 \mathrm{~h}$ later. The subjects that failed to learn in the 1st day of training received a 2 nd and, when necessary, a 3rd day of training. The animals that did not reach the learning criterion after 3 consecutive days of training were discarded for this part of the study. Variables recorded were number of effective (i.e., rewarded) leverpresses made with each forepaw and number of complete rotations of the whole body towards or away from the side of the brain injected at surgery.

Following the operant behavior experiment, five lesioned and six vehicle-injected subjects that had successfully learned and performed the operant response were returned to the individual cages. They were allowed 7 days in these cages before recorded observation was resumed. This part of the study lasted 7 days, and consisted of regular daily measurements of food intake and food spillage. Body weight was not measured, because the aim of this part of the study was to ascertain whether or not high food spillage, which had been regarded tentatively as indicative of sensorimotor dysfunction, was still evident in the lesioned animals, so that food spillage habits could be compared with observations made in the operant behavior situation.

\section{Surgery}

The animals were pretreated for $30 \mathrm{~min}$ with $50 \mathrm{mg} / \mathrm{kg}$ pargyline and $25 \mathrm{mg} / \mathrm{kg}$ desipramine and then anesthetized with halothane. Then 6-hydroxydopamine ( $8 \mu \mathrm{g}$ of the base in $4 \mu \mathrm{l}$ ) or vehicle (L-ascorbic acid $2 \mu \mathrm{g}$ in $4 \mu \mathrm{l}$ isotonic saline) was injected into the MFB of left or right hemisphere, using the following coordinates: $4.1 \mathrm{~mm}$ behind the bregman, $1.1 \mathrm{~mm}$ lateral to the midline, and $7.6 \mathrm{~mm}$ below the cortical surface. Intracranial injections were administered at the rate of $1 \mu 1 / \mathrm{min}$, with the help of a Hamilton syringe fixed to a motorised injecting device. After each injection, 4 min were allowed to elapse before the injection cannula was withdrawn.

\section{Biochemical Analysis}

All subjects were sacrificed 15 weeks after surgery by cervical disloration. Their brains were rapidly removed and cooled in saline at $0^{\circ} \mathrm{C}$. A knife cut was made through the brain perpendicular to the cortical surface at the level of the optic chiasma. The septal area was cut away from the block of brain tissue anterior to the coronal knife cut, and the two striatal samples were then separated out. The rest of the block of tissue was then separated down the midline to obtain the two "mesolimbic" samples, consisting of frontal cortex, olfactory tubercle, and nucleus accumbens. All the samples were stored in liquid nitrogen until assayed for dopamine and norepinephrine contents by a modification of the radioenzymatic method of Coyle and Henry (1973) and Palkovitz, Brownstein, Saavedra, and Axelrod (1974).

\section{RESULTS}

\section{Feeding Behavior and Body Weight Regulation}

Lesioned animals suffered a sharp drop in body weight, and remained underweight throughout the period when body weights were being measured. This observation is reflected in the mean rates of increases in body weight displayed by the lesioned and the vehicle-injected groups of subjects before and for 2 weeks after surgery (Table 1). Statistical treatment of the data using the Mann-Whitney $\mathrm{U}$ test revealed no significant differences between the two groups prior to surgery, but showed that the lesioned group gained significantly less weight than the vehicle-injected group during the 1st postoperative week $(\mathrm{p}=.001$, one-tailed test), and also during the 2 nd postoperative week $(\mathrm{p}=.01$, one-tailed test).

Lesioning also resulted in a sustained reduction of food intake (Table 1). Although food intake was not significantly different between the lesioned and vehicle-injected groups before surgery (Mann-Whitney $U$ test), the lesioned group ingested significantly less food during the 1st postoperative week, during the 2 nd postoperative week, during the $24 \mathrm{~h}$ of poststarvation feeding, and during the 1 week of recorded observations approximately 3 months after surgery $(p=.001$, one-tailed test).

Food spillage was also affected by unilateral MFB damage (Table 1). The Mann-Whitney U test revealed a significant difference between the lesioned and the vehicleinjected groups of rats in the mean ratios of food spilled to food attempted during the 1st postoperative week, the 2 nd postoperative week, the $24 \mathrm{~h}$ of poststarvation feeding, and the 1 week of recorded observation that occurred 3 months after surgery ( $p=.001$, one-tailed test), although there was no significant difference between the two subject groups in this regard prior to surgery.

\section{Behavior in the Operant Chamber}

Although the vehicle-injected animals attained the criterion of learning on the 1st day of training, two of the seven lesioned subjects failed to reach criterion in 3 days. Of the five experimental subjects reaching criterion, only one did so on the 1st day of training; another appeared to have reached criterion by the end of the 1st day of training, but failed to show any signs of learning when tested the following day, although it finally did learn by the 3rd day. The other three experimental subjects that attained the criterion of learning did so on the 3rd day

Table 1

Mean Body Weight Increases, Food Intake, and Food Spillage in Lesioned and Vehicle-Microinjected Groups of Rats Before and After Surgery

\begin{tabular}{lcc}
\hline Chronology & $\begin{array}{c}\text { Lesioned } \\
\text { Rats }\end{array}$ & $\begin{array}{c}\text { Control } \\
\text { Rats }\end{array}$ \\
\hline \multicolumn{3}{c}{ Mean \pm SD of Body Weight Increases* } \\
1 Week Before Surgery & $30 \pm 2$ & $31 \pm 3$ \\
1st Postsurgery Week & $18 \pm 6$ & $40 \pm 4$ \\
2nd Postsurgery Week & $24 \pm 7$ & $34 \pm 9$ \\
\multicolumn{3}{c}{ Mean \pm SD of Intake* } \\
1 Week Before Surgery & $151 \pm 9$ \\
1st Postsurgery Week & $103 \pm 10$ & $142 \pm 6$ \\
2nd Postsurgery Week & $146 \pm 12$ & $155 \pm 9$ \\
24 h Following Deprivation & $28 \pm 3$ & $194 \pm 10$ \\
14th Postsurgery Week & $172 \pm 13$ & $33 \pm 4$ \\
\multicolumn{4}{c}{ Mean \pm of Spillage** } \\
1 Week Before Surgery & $0.14 \pm 0.01$ & $202 \pm 19$ \\
1st Postsurgery Week & $0.35 \pm 0.11$ & $0.13 \pm 0.03$ \\
2nd Postsurgery Week & $0.33 \pm 0.10$ & $0.17 \pm 0.03$ \\
24 h Following Deprivation & $0.35 \pm 0.10$ & $0.17 \pm 0.02$ \\
14th Postsurgery Week & $0.23 \pm 0.04$ & $0.15 \pm 0.02$ \\
\hline Note $-N=5$-7 per group. & $*$ In grams. & $* *$ As a ratio of food
\end{tabular}


of training. One of the animals that failed to reach criterion during the 3 days of training seemed to have learned by the end of the 1st day of training, but never showed signs of learning after that day.

All five lesioned subjects that learned used virtually only the forepaw on the same side as the lesion when they operated the lever. The vehicle-injected controls, on the other hand, displayed a random pattern of forepaw use, three subjects pushing the lever predominantly, although not entirely, with the ipsilateral forepaw, and the other three mostly with the contralateral forepaw. Rate of leverpressing was significantly lower in the lesioned than in the vehicle-injected group ( $\mathrm{p}=.005$, Mann-Whitney $\mathrm{U}$ test, one-tailed). The patterns of forepaw use and the rates of leverpressing exhibited by the two subject groups are presented in Figures $1 \mathrm{~A}$ and $1 \mathrm{~B}$.

Presented in Figure $1 \mathrm{C}$ are the mean numbers of ipsiversive versus contraversive spontaneous rotations performed by the two groups over $20 \mathrm{~min}$ of testing in the operant chamber. Four of the experimental subjects performed between 10 and 29 rotations each, and rotated exclusively toward the lesioned side; the one remaining experimental subject rotated only 6 times, but all its rotations were also ipsiversive. The six vehicle-injected rats performed between 1 and 7 rotations each and the direction of circling was randomly distributed among the animals and in three cases in the same animals as well.

The lesioned rats performed significantly more rotations than the vehicle-injected controls ( $p=.005$, MannWhitney U test, one-tailed).
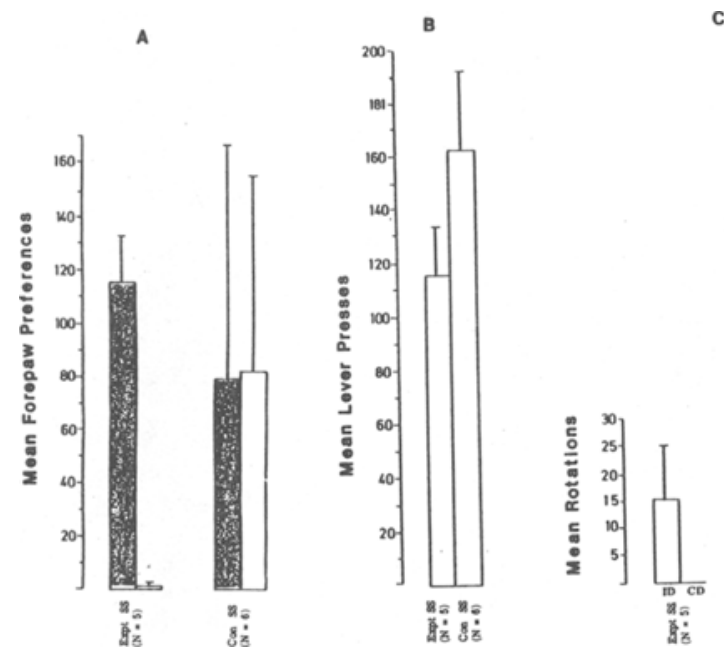

c

Figure 1. Mean forepaw preferences (A), leverpresses (B), and rotations to each side $(C)$ displayed for a 20 -min operant behavior session by the lesioned and vehicle-injected groups of rats trained approximately 13 weeks after surgery. The columns in A represent the mean number of effective leverpresses executed by each group with the forepaw ipsilateral (stippled columns) or contralateral (open columns) to the operated hemisphere. Each bar represents 1 SD. Abbreviations: Expt. SS, lesioned group of rats; Con SS, vehicleinjected group of rats; ID, mean ipsiversive rotations; and CD, mean contraversive rotations.

\section{Correlational Analysis}

The Pearson product-moment correlational method was used to analyse the data from the operant chamber experiment vis-a-vis feeding behavior in the immediately succeeding week. There was no significant correlation in either the lesioned group or the control group between food intake and leverpresses or rotations (lesioned group, $\mathrm{df}=3: \mathrm{r}=-.860$ for food intake vs. leverpresses and $r=.857$ for food intake vs. rotation; control group, $\mathrm{df}$ $=4: \mathrm{r}=.439$ for food intake vs. leverpresses and $\mathrm{r}=$ .058 for food intake vs. rotations) or between spillage and leverpresses or rotations (lesioned group, $\mathrm{df}=3: \mathbf{r}=$ .030 for food spillage vs. leverpresses and $r=.051$ for food spillage vs. rotations; control group, $\mathrm{df}=4$ : food $r=-.706$ for spillage vs leverpresses and $r=.696$ for food spillage vs. rotations).

\section{Catecholamine Assay Results}

The dopamine and norepinephrine assay results are shown in Table 2 . The results are calculated and presented as percentages of dopamine or norepinephrine values obtained from corresponding brain samples in the unlesioned hemisphere. All seven lesioned animals suffered a neartotal loss of striatal dopamine on the lesion side. Norepinephrine content of the ipsilateral striatum and dopamine content of the ipsilateral "mesolimbic" area were also reduced in these subjects. Mesolimbic norepinephrine was, however, largely spared by the lesion in these rats. The six vehicle-injected controls did not suffer a consistent loss of dopamine or norepinephrine in the ipsilateral mesolimbic area or striatum.

\section{DISCUSSION}

In this study, unilateral MFB damage depressed body weight and the rate of body weight increase (Table 1). This finding is in agreement with the report of Baez and his coworkers (Baez et al., 1977), and the observed depression of food intake in the lesioned animals confirms these authors' speculation that the lesion-induced depression of body weight was probably due to reduced food intake.

Unilateral lesions which disrupt the nigrostriatal dopamine system have already been shown to produce a variety of sensorimotor deficits (Marshall et al., 1974), including the impairment of an animal's ability to use its contralateral forepaw to operate a lever for food in an operant chamber (Hansing, Schwartzbaum, \& Thompson, 1968; Uguru-Okorie, 1982; Uguru-Okorie \& Arbuthnott, 1981).

In the present study, the effect of unilateral MFB damage on the performance of learned food-rewarded leverpressing was twofold. First, all the lesioned animals operated the lever with virtually only the forepaw on the same side as the lesioned hemisphere, whereas the vehicleinjected rats displayed a random pattern of forepaw use. Second, the lesioned group executed significantly fewer 
Table 2

Mean \pm SD Percent Catecholamine Reductions in the Injected Hemisphere of 6-Hydroxydopamine-Lesioned and Control Rats

\begin{tabular}{|c|c|c|c|}
\hline \multicolumn{2}{|c|}{ Dopamine } & \multicolumn{2}{|c|}{ Norepinephrine } \\
\hline Striatal & Mesolimbic & Striatal & Mesolimbic \\
\hline \multicolumn{4}{|c|}{ Lesioned (Experimental) Group $(\mathrm{N}=7)$} \\
\hline $100 \pm 0$ & $98 \pm 0$ & $93 \pm 5$ & $28 \pm 38$ \\
\hline \multicolumn{4}{|c|}{ Vehicle-Injected (Control) Group $(\mathrm{N}=6)$} \\
\hline $7 \pm 7$ & $9 \pm 11$ & $9 \pm 12$ & $15 \pm 16$ \\
\hline
\end{tabular}

effective presses than the control group in $20 \mathrm{~min}$ of recorded observation. The almost exclusive use of the ipsilateral forepaw observed in the lesioned subjects may be related to the earlier finding that unilateral nigrostriatal damage causes sensorimotor impairments evident on the side of the body contralateral to that of the lesioned hemisphere (Ljungberg \& Ungerstedt, 1976; Marshall et al., 1974; Uguru-Okorie, 1982). The low rate of effective leverpresses displayed by the lesioned group, as compared to controls, is reminiscent of akinesia such as has been reported following bilateral damage (Oltmans \& Harvey, 1972; Ungerstedt, 1971; Zigmond \& Stricker, 1972). However, the fact that the lesioned animals were rendered subject to persistent circling may have contributed to their low rate of leverpressing. Rotation takes time and number of leverpresses obviously depends to some extent upon the amount of time available for the leverpressing operation.

The observation that lesioned subjects generally took longer than controls to reach learning criterion appears to support the finding by Ranje and Ungerstedt (1977) that bilateral nigrostriatal damage impairs the capacity to acquire some kinds of learning (they used brightness and spatial discrimination tasks). However, it should be noted that in the present study rats with unilateral MFB damage displayed a tendency to rotate frequently (Figure 1), and that this may have reduced their chances of making the prerequisite association between leverpressing and the availability of food at the food tray. In view of this, the delay in learning exhibited by the lesioned animals may not justifiably be explained, on the basis of the present study, in terms of a fundamental disruption of the capacity to learn.

The demonstration in this study of lesion-induced effects in the same set of animals was the empirical outcome of an attempt to examine the relatedness or otherwise of these same observations as previously separately recorded in different studies of feeding (Uguru-Okorie, 1981) and operant chamber behavior (Uguru-Okorie, 1982). However, statistical analysis did not reveal any significant correlation between food intake or spillage levels, on the one hand, and number of leverpresses or rotations, on the other. Even the data on food intake and spillage were not significantly correlated.

Food spillage, leverpressing, and rotation are activities that, like food intake, obviously have a sensorimotor component. The absence of significant correlations between food intake and these other activities appears to suggest that lesion-induced depression of food intake is not mediated entirely through any general sensorimotor deficits. It is proposed that the depression of food intake observed in the lesioned animals may be a behavioral change that is distinct from and partly independent of changes in food spillage, forepaw use, and rotation.

\section{REFERENCES}

Baez, L. A., Ahlskog, J. E., \& Randall, P. K. (1977). Body weight and regulatory deficits following unilateral nigrostriatal lesion. Brain Research, 132, 467-476.

BoYle, P. C. , \& KeEsey, R. E. (1975). Chronically reduced body weight in rats sustaining lesions of the lateral hypothalamus and maintained on palatable diets and drinking solutions. Journal of Comparative and Physiological Psychology, 88, 218-223.

Coyle, J. T., \& HeNry, D. (1973). Catecholamines in fetal and new-born rat brain. Journal of Neurochemistry, 21, 61-67.

FIbIGER, H. C. , ZIS, A. P., \& MCGEER, E. G. (1973a). Feeding and drinking deficits after 6-hydroxydopamine administration in the rat: Similarities to the lateral hypothalamic syndrome. Brain Research, 55, 123-134.

Fibiger, H. C., Zis, A. P., \& McGeER, E. G. (19/3b). Feeding and drinking deficits after 6-hydroxydopamine administration in the rat: Similarities to the lateral hypothalamic syndrome. Brain Research, 55, 135-148.

Hansing, R. A., Schwartzbaum, J. S., \& Thompson, J. B. (1968). Operant behaviour following unilateral and bilateral caudate lesions in the rat. Journal of Comparative and Phyhsiological Psychology, 66, 378-388.

LJUNGBERG, T., \& UNGERSTEDT, U. (1976). Sensory inattention produced by 6-hydroxydopamine-induce degeneration of ascending doparnine neurons in the brain. Experimental Neurology, 53, 585-600.

Marshall, J. F., Richardson, J. S., \& Teitelbalm, P. (1974). Nigrostriatal bundle damage and the lateral hypothalamic syndrome. Journal of Comparative and Physiological Psychology, 87, 808-830.

Oltmans, G. A., \& HaRvey, J. A. (1972). LH syndrome and brain catecholamine levels after lesions of the nigrostriatal bundle. Physiology \& Behaviour, 8, 69-78.

Palkovitz, M., Brownstein, M., SaAvedra, J. M., \& Axelrod, J. (1974). Norepinephrine and dopamine content of hypothalamic nuclei of the rat. Brain Research, 77, 137-149.

POWley, T. L., \& KEESEY, R. E. (1970). Relationship of body weight to the lateral hypothalamic feeding syndrome. Journal of Comparative and Physiological Psychology, 70, 25-36.

RANJE, C., \& UNGERSTEDT, U. (1977). Lack of acquisition in dopamine denervated animals tested in an underwater Y-maze. Brain Research, 134, 95-111.

Uguru-OKORIE, D. C. (1981). An experimental analysis of the feeding and body weight effects of a unilateral 6-hydroxydopamine lesion of the medial forebrain bundle in the rat. Physiological Psychology, 9, 187-192.

Uguru-OkorIE, D. C. (1982). Nigrostriatal dopaminergic control of operant and spatial behaviour in the rat. Physiological Psychology, 10, 97-107.

Uguru-Okorie, D. C. , \& Arbuthnott, G. W. (1981). Altered paw preference after unilateral 6-hydroxydopamine injections into lateral hypothalamus. Neuropsychologia, 19, 463-467.

UNGERSTEDT, U. (1971). Adipsia and aphagia after 6-hydroxydopamine induced degeneration of the nigrostriatal dopamine system in the rat brain. Acta physiologica Scandinavica Supplementum, 367, 95-122.

Zigmond, M. J., \& STRICKer, E. M. (1972). Deficits in feeding behavior after intraventricular injections of 6-hydroxydopamine in rat. Science, 177, $1211-1214$.

(Manuscript received September 12, 1983; revision accepted for publication June 10, 1984.) 